\title{
The Synthesis, Structures and Characterisation of New Mixed-Ligand Manganese and Iron Complexes with Tripodal, Tetradentate Ligands
}

\author{
Remy van Gorkum, ${ }^{[a]}$ Joris Berding, ${ }^{[a]}$ Allison M. Mills, ${ }^{[b]}$ Huub Kooijman, ${ }^{[b]}$ \\ Duncan M. Tooke, ${ }^{[b]}$ Anthony L. Spek, ${ }^{[b]}$ Ilpo Mutikainen, ${ }^{[c]}$ Urho Turpeinen, ${ }^{[c]}$ \\ Jan Reedijk, ${ }^{\text {[a] }}$ and Elisabeth Bouwman*[a]
}

Keywords: Tripodal ligands / Iron / Manganese

The preparation of new manganese and iron complexes with the general formula [M(tripod)(anion)] is described, where $\mathrm{M}$ $=\mathrm{Fe}^{\mathrm{III}}$ or $\mathrm{Mn}^{\mathrm{III}}$, "tripod" is a dianionic tetradentate tripodal ligand and the anion is a chelating $\beta$-diketonate, 8-oxyquinoline or acetate. The synthesis of this type of complexes was found to be straightforward, which allows for the preparation of a large variety of such coordination compounds. The complexes are characterised by X-ray crystallography, infrared spectroscopy, UV/Vis spectroscopy, cyclic voltammetry and elemental analysis. A correlation between the ligand sets and the electron density at the metal centre in the complexes is proposed, based on the UV/Vis data and the CV measurements. The tripodal ligands are significant $\pi$-donor ligands, and electron-withdrawing or electron-donating substituents on the phenolate arms were found to have a large influence on both the position of the $\mathrm{d}-\mathrm{d}$ transitions in the UV/Vis spectra and the peak potentials in the CV measurements. The "secondary" $\beta$-diketonate or acetate ligand does not have such a large effect on the electron density of the metal centre.

(๔ Wiley-VCH Verlag GmbH \& Co. KGaA, 69451 Weinheim, Germany, 2008)

\section{Introduction}

Tripodal ligands have been used abundantly in the synthesis of metal complexes as model systems for the active site of various enzymes. Chelating ligands in which one or more of the "arms" consist of phenol groups have been used extensively for the preparation of copper complexes that model the active site of the enzyme galactose oxidase, ${ }^{[1-5]}$ and also in the synthesis of iron and manganese complexes to model the active sites of various dioxygenase and phosphatase enzymes. ${ }^{[6-11]}$ Lipoxygenases are nonheme, non-sulfur iron or manganese dioxygenases that act on lipid substrates containing one or more $(Z, Z)-1,4$-pentadiene moieties. ${ }^{[12]}$ Common polyunsaturated fatty acids, such as linoleic, linolenic and arachidonic acids are the natural substrates for these enzymes, which are widely distributed among plants and animals. The primary reaction products are hydroperoxides of conjugated $(E, Z)$-dienes, which is why model complexes for the lipoxygenase active

[a] Leiden Institute of Chemistry, Gorlaeus Laboratories, Leiden University,

P. O. Box 9502, 2300 RA Leiden, The Netherlands

Fax: +31-71-5274451

E-mail: bouwman@chem.leidenuniv.nl

[b] Bijvoet Center for Biomolecular Research, Crystal and Structural Chemistry, Utrecht University, The Netherlands

[c] Laboratory of Inorganic Chemistry, Department of Chemistry, University of Helsinki,

P. O. Box 55, (A.I.Virtasen aukio 1), 00014 Helsinki, Finland

Supporting information for this article is available on the WWW under http://www.eurjic.org/ or from the author. site could thus very well be good catalytic driers for alkyd paints, especially if they are also able to catalytically decompose hydroperoxides. The aim of our research is to find new, metal complex based driers for alkyd paints, not containing cobalt. ${ }^{[13-15]}$ The use of cobalt compounds in paints is a topic of concern, due to the toxicity and suspected carcinogenity of cobalt. ${ }^{[16-19]}$ The active site of the lipoxygenase enzyme has been modelled by iron complexes using tripodal ligands with exclusively nitrogen donor atoms. ${ }^{[20-23]}$

The general motivation for using tripodal ligands in the development of paint-drying catalysts is that such large, tetradentate ligands usually form very stable complexes with manganese and iron. The structure of the formed complexes is thus expected to be "robust" and not easily destroyed under oxidising conditions. This last point is especially important, since the complexes that are made with these ligands have to function as radical autoxidation catalysts and are thus subject to extremely oxidising conditions. An additional benefit of the used ligand type is that the synthesis of the ligands is straightforward and variations on the ligand structure are easily made. The tripodal ligands that have been prepared all have one or two (substituted) phenol groups. Consequently, these ligands can coordinate as mono- or dianions. $\beta$-Diketonates were chosen as the "secondary" ligand, because good autoxidation results were obtained with simple, homoleptic manganese $\beta$-diketonate complexes. ${ }^{[13,24]}$

The complexes that are presented in this manuscript are manganese(III) or iron(III) coordination compounds with 
one dianionic tripodal ligand (Scheme 1) and one $\beta$-diketonate ligand; some complexes have been prepared containing an anionic ligand such as 8-oxyquinoline or acetate instead of the $\beta$-diketonate. The resulting complexes are noncharged, which is expected to increase their solubility in apolar solvents. For potential paint driers a good solubility in the apolar paint medium is considered to be one of the most crucial properties. ${ }^{[25]}$

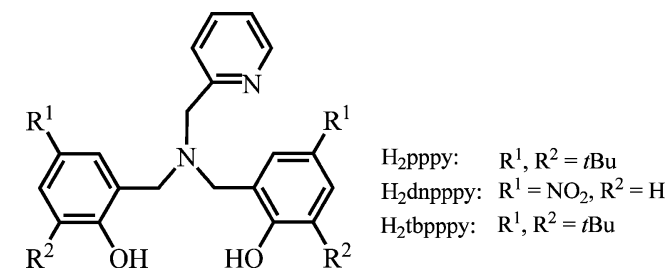

Scheme 1. Tripodal ligands used in this study.

\section{Results and Discussion}

Two strategies are commonly used to prepare tripodal ligands based on a tertiary amine: By nucleophilic substitution of a chloro(bromo)alkyl group with a primary or secondary amine or through reductive amination, i.e. reaction of an aldehyde with an appropriate amine, followed by reduction of the formed Schiff-base compound. The ligands $\mathrm{H}_{2}$ pppy and $\mathrm{H}_{2}$ dnpppy have been prepared using the reductive amination. The ligand $\mathrm{H}_{2}$ pppy was obtained in $27 \%$ yield according to the reported method. ${ }^{[26]}$ The ligand $\mathrm{H}_{2}$ dnpppy has been reported coordinated as a ligand in copper and iron complexes, ${ }^{[27,28]}$ but not as purified and isolated molecule. Although $\mathrm{H}_{2}$ dnpppy was obtained in high purity, the overall yield was quite low, being only $14 \%$.

The ligand $\mathrm{H}_{2}$ tbpppy was prepared in one step using the Mannich reaction; 2-aminomethylpyridine was treated with 2,4-di-tert-butylphenol and paraformaldehyde in refluxing ethanol. Both the ligand and the used reaction method have been reported in literature. ${ }^{[2]}$ The literature method was followed with the differences that the quantity of the reagents was doubled, as was the reagent concentration in the reaction mixture and the reaction time. This resulted in a higher yield of $71 \%$, vs. $56 \%$ reported in literature.

\section{Complex Synthesis}

The obtained complexes have the general formula [M(tripod)(anion)], in which $\mathrm{M}$ is $\mathrm{Fe}^{\mathrm{III}}$ or $\mathrm{Mn}^{\mathrm{III}}$, "tripod" is one of the dianionic ligands pppy, dnpppy, or tbpppy and "anion" is a bidentate monoanionic ligand such as 8oxyquinoline (quin), acetate (OAc), or one of the $\beta$-diketonates 2,4-pentanedionate (acac), 1,3-diphenylpropane-1,3-dionate $(\mathrm{dbm})$ and 2,2,6,6-tetramethyl-3,5-heptanedionate (dpm). An overview of the synthesised complexes is given in Scheme 2.
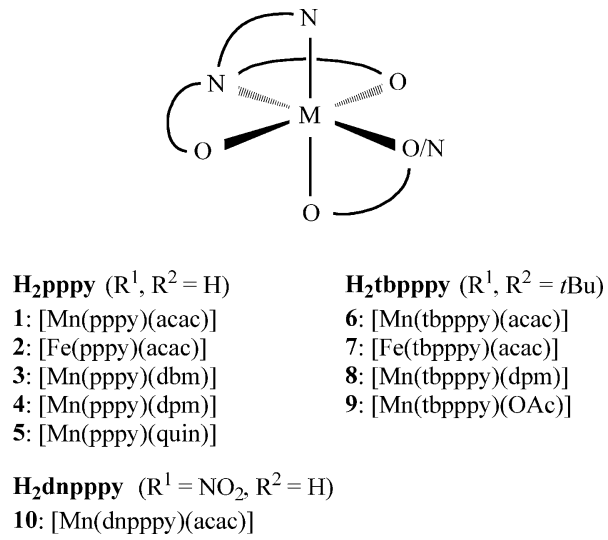

Scheme 2. Overview of the synthesized complexes.

The general method used to prepare these complexes was to react a $\left[\mathrm{M}(\beta \text {-diketonate })_{3}\right]$ complex with the tripodal ligand in an appropriate solvent (typically $\mathrm{CH}_{2} \mathrm{Cl}_{2}$ or $\mathrm{CHCl}_{3}$ ) with the addition of triethylamine. Alternatively, complex 4, $\left[\mathrm{Mn}^{\mathrm{III}}(\mathrm{pppy})(\mathrm{dpm})\right]$, could also be prepared by addition of 1 equiv. of Hdpm and 1 equiv. of $\mathrm{H}_{2}$ pppy to the manganese salt $\left[\mathrm{Mn}^{\mathrm{II}}\left(\mathrm{H}_{2} \mathrm{O}\right)_{6}\right]\left(\mathrm{ClO}_{4}\right)_{2}$ in $\mathrm{CH}_{2} \mathrm{Cl}_{2}$ solution in the presence of 2 equiv. of triethylamine. Complex $5, \mathrm{Mn}^{\mathrm{III}}$ (pppy)(quin)], was also prepared using the latter method. Complex 9, [Mn $\left.{ }^{\mathrm{III}}(\mathrm{tbpppy})(\mathrm{OAc})\right]$, was prepared according to the general method employed for $\beta$-diketonate containing complexes but using manganese(III) acetate as a starting compound.

The yields vary greatly (10-90\%), but no attempts have been undertaken to optimise the yield for each individual complex. Since only a very small amount of complex is necessary to examine its autoxidation activity, ${ }^{[14,29]}$ obtaining pure compounds was given higher priority than maximising the yields.

\section{Description of the Structures}

Single crystals were obtained for the complexes 1-5 and 9, and their structures have been determined. The molecular structures of the complexes 1-5 and $\mathbf{9}$ are depicted in Figure 1. A selection of bond lengths and angles is given in Table 1 and Table 2.

The asymmetric units of $\mathbf{1}$ and $\mathbf{4}$ contain two independent molecules. Although some bond lengths and angles vary slightly for the two complexes in the asymmetric unit, only the data for one of the independent molecules are given in Table 1. For the three related complexes 1, $\mathbf{3}$ and $\mathbf{4}$ the bond lengths are rather similar. The manganese(III) ion has a somewhat distorted octahedral coordination environment. The equatorial plane is composed of the two phenolate oxygen atoms of the tripodal ligand, the tertiary amine nitrogen and one of the $\beta$-diketonate oxygen donors. The axial positions are occupied by the other $\beta$-diketonate oxygen atom and the pyridyl nitrogen atom. The larger axial bond lengths, Mn1-N31 and Mn1-O46 are consistent with a Jahn-Teller distortion, as is expected for a high-spin octa- 


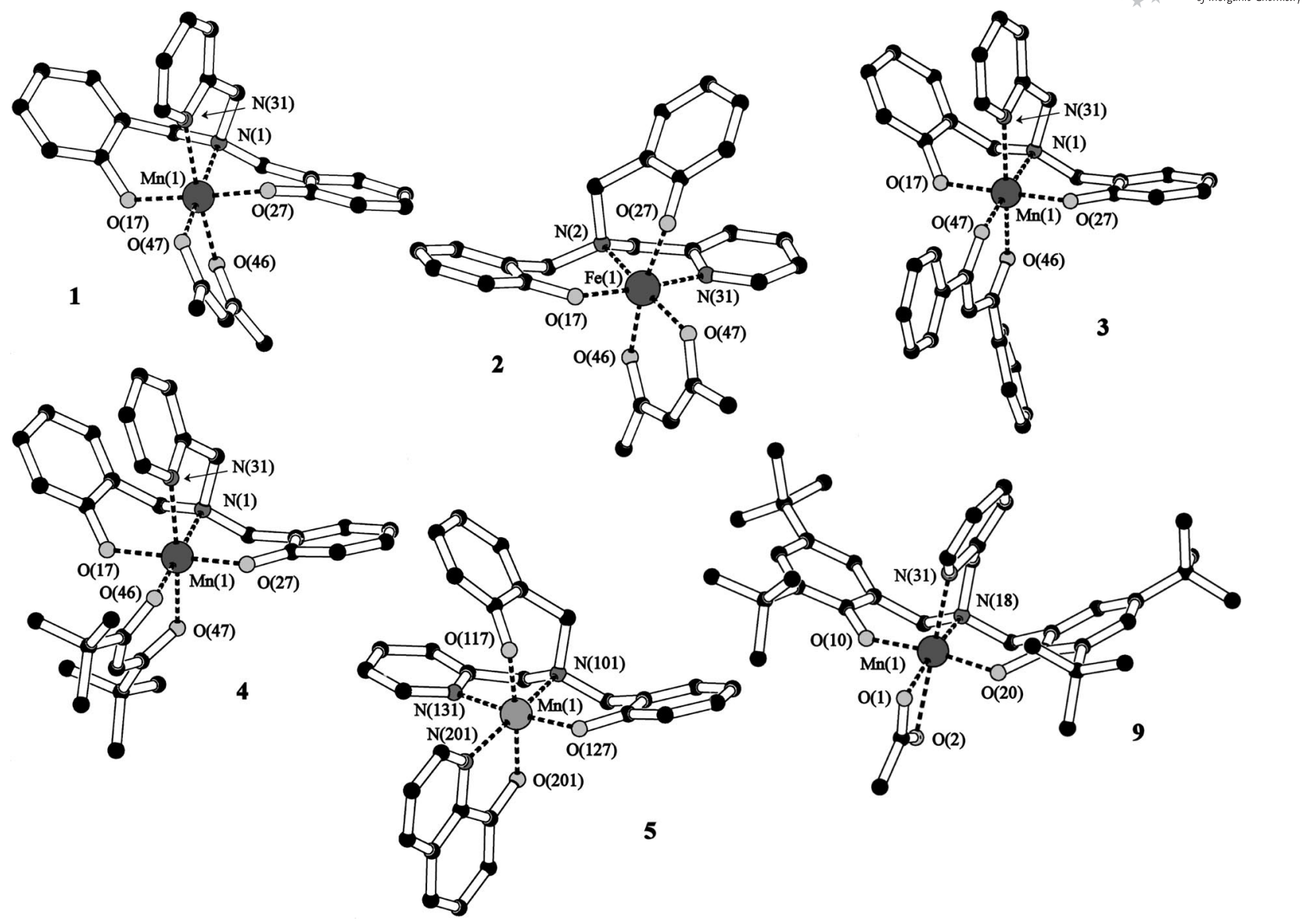

Figure 1. Projections of the molecular structures of [Mn(pppy)(acac)] (1); [Fe(pppy)(acac)] (2); [Mn(pppy)(dbm)] (3); [Mn(pppy)(dpm)] (4); [Mn(pppy)(quin)] (5); [Mn(tbpppy)(OAc)] (9). Hydrogen atoms have been omitted for clarity.

Table 1. Selected bond lengths $[\AA]$ and angles $\left[{ }^{\circ}\right]$ for $\mathbf{1}, \mathbf{3}$ and $\mathbf{4}$.

\begin{tabular}{llll}
\hline & $\mathbf{1}$ & $\mathbf{3}$ & $\mathbf{4}$ \\
\hline Mn1-N1 & $2.1631(15)$ & $2.1425(11)$ & $2.104(5)$ \\
Mn1-N31 & $2.2281(17)$ & $2.2205(11)$ & $2.231(5)$ \\
Mn1-O17 & $1.8894(13)$ & $1.8703(10)$ & $1.870(4)$ \\
Mn1-O27 & $1.8672(13)$ & $1.8739(10)$ & $1.873(4)$ \\
Mn1-O46 & $2.0843(14)$ & $2.1145(9)$ & $2.112(4)$ \\
Mn1-O47 & $2.0230(13)$ & $1.9854(11)$ & $1.969(4)$ \\
N1-Mn1-N31 & $78.11(6)$ & $78.46(4)$ & $79.38(19)$ \\
O17-Mn1-O27 & $177.52(6)$ & $175.00(4)$ & $177.70(17)$ \\
O17-Mn1-O46 & $91.14(6)$ & $89.86(4)$ & $87.22(17)$ \\
O17-Mn1-O47 & $91.47(5)$ & $87.83(4)$ & $88.73(18)$ \\
O17-Mn1-N1 & $91.85(6)$ & $93.26(4)$ & $92.12(18)$ \\
O17-Mn1-N31 & $91.30(6)$ & $86.38(4)$ & $86.90(17)$ \\
O27-Mn1-O46 & $90.46(6)$ & $93.76(5)$ & $94.02(17)$ \\
O27-Mn1-O47 & $90.48(5)$ & $88.89(4)$ & $89.40(18)$ \\
O27-Mn1-N1 & $86.08(6)$ & $90.04(4)$ & $89.67(18)$ \\
O27-Mn1-N31 & $86.93(6)$ & $90.60(5)$ & $92.02(17)$ \\
O46-Mn1-O47 & $88.25(6)$ & $87.46(4)$ & $87.10(17)$ \\
O46-Mn1-N1 & $96.26(6)$ & $92.28(4)$ & $96.06(18)$ \\
O46-Mn1-N31 & $173.94(6)$ & $169.77(4)$ & $172.41(19)$ \\
O47-Mn1-N1 & $174.34(6)$ & $178.88(4)$ & $176.77(17)$ \\
O47-Mn1-N31 & $97.23(6)$ & $101.88(4)$ & $97.56(18)$ \\
folding angle over O46-O47 & $21.60(9)$ & $7.99(6)$ & $31.2(2)$ \\
\hline
\end{tabular}

hedral $\mathrm{d}^{4}$ metal ion. The Mn1-O(phenolato) distances fall within the range reported for related $\mathrm{Mn}^{\mathrm{III}}-\mathrm{O}$ (phenolato) distances. ${ }^{[30]}$ To accommodate the relatively short $\mathrm{Mn}^{\mathrm{II}}$
$\mathrm{O}$ (phenolato) distances the two six-membered chelate rings containing manganese, a phenolate oxygen atom and the tertiary amine nitrogen atom are significantly puckered. The difference in molecular structure for each of the compounds $\mathbf{1}, \mathbf{3}$ or $\mathbf{4}$ is obviously related to the different $\beta$ diketonate ligand that is coordinated in each of the complexes. In all three complexes the $\beta$-diketonate ligand is coordinated asymmetrically, with the longest $\mathrm{Mn}-\mathrm{O}$ distance trans to the pyridine nitrogen in the axial position. The asymmetry is more pronounced in complexes $\mathbf{3}$ and $\mathbf{4}$. The least-squares plane defined by the atoms of the acac ligand in 1 makes an acute angle of $21.60^{\circ}$ with the plane defined by Mn1-O46-O47. Such a slight folding of the chelate ring is frequently observed for $\beta$-diketonate ligands and is commonly attributed to packing effects in the crystal lattice. ${ }^{[31]}$ Similarly, the dpm ligand in $\mathbf{4}$ is folded over the O46-O47 axis, with a folding angle that is notably larger than for acac in 1, being $31.2(2)^{\circ}$. This observation is in agreement with the assumption that the folding is a consequence of the crystal packing, since the dpm ligand is considerably more bulky than the acac ligand. The $\mathrm{dbm}$ ligand in complex $\mathbf{3}$ is also slightly folded, but the folding angle is the smallest of the three complexes, being only $7.99(6)^{\circ}$.

Complex 2 is an iron(III) complex that has the same ligand set as complex $\mathbf{1}$. In contrast to complex $\mathbf{1}$, the two 
Table 2. Selected bond lengths [Å] and angles [ $\left.{ }^{\circ}\right]$ for the complexes $\mathbf{2 , 5}$ and $\mathbf{9}$.

\begin{tabular}{|c|c|c|c|c|c|}
\hline 2 & & 5 & & 9 & \\
\hline $\mathrm{Fe} 1-\mathrm{N} 2$ & $2.1972(15)$ & Mn1-N101 & $2.237(3)$ & Mn1-N18 & $2.095(4)$ \\
\hline $\mathrm{Fe} 1-\mathrm{N} 31$ & $2.181(2)$ & Mn1-N131 & $2.110(3)$ & Mn1-N31 & $2.223(4)$ \\
\hline $\mathrm{Fe} 1-\mathrm{O} 17$ & $1.9047(16)$ & Mn1-O117 & $1.8794(19)$ & Mn1-O10 & $1.844(4)$ \\
\hline $\mathrm{Fe} 1-\mathrm{O} 27$ & $1.9299(15)$ & Mn1-O127 & $1.896(2)$ & Mn1O20 & $1.867(4)$ \\
\hline $\mathrm{Fe} 1-\mathrm{O} 46$ & $2.0948(15)$ & $\mathrm{Mn} 1-\mathrm{O} 201$ & $1.9133(19)$ & $\mathrm{Mn} 1-\mathrm{O} 2$ & $2.351(4)$ \\
\hline $\mathrm{Fe} 1-\mathrm{O} 47$ & $1.9924(15)$ & Mn1-N201 & $2.236(3)$ & Mn1-O1 & $1.998(4)$ \\
\hline N2-Fe1-N31 & 77.17(7) & N101-Mn1-N131 & $78.28(12)$ & N18-Mn1-N31 & $78.93(15)$ \\
\hline $\mathrm{O} 17-\mathrm{Fe} 1-\mathrm{O} 27$ & $100.18(7)$ & O117-Mn1-O127 & $91.33(9)$ & $\mathrm{O} 10-\mathrm{Mn} 1-\mathrm{O} 20$ & $173.20(14)$ \\
\hline O17-Fe1-O46 & $91.66(6)$ & O117-Mn1-O201 & $175.46(13)$ & O10-Mn1-O2 & $86.19(16)$ \\
\hline O17-Fe1-O47 & $100.18(6)$ & O117-Mn1-N201 & $97.50(11)$ & O10-Mn1-O1 & $87.09(15)$ \\
\hline $\mathrm{O} 17-\mathrm{Fe} 1-\mathrm{N} 2$ & $88.83(7)$ & O117-Mn1-N101 & $90.35(10)$ & O10-Mn1-N18 & $91.82(18)$ \\
\hline O17-Fe1-N31 & $165.08(7)$ & O117-Mn1-N131 & $89.56(9)$ & O10-Mn1-N31 & $96.06(17)$ \\
\hline $\mathrm{O} 27-\mathrm{Fe} 1-\mathrm{O} 46$ & $168.15(7)$ & O127-Mn1-O201 & $92.28(9)$ & $\mathrm{O} 20-\mathrm{Mn} 1-\mathrm{O} 2$ & $87.46(16)$ \\
\hline $\mathrm{O} 27-\mathrm{Fe} 1-\mathrm{O} 47$ & $92.13(6)$ & O127-Mn1-N201 & $96.44(11)$ & $\mathrm{O} 20-\mathrm{Mn} 1-\mathrm{O} 1$ & $87.62(15)$ \\
\hline $\mathrm{O} 27-\mathrm{Fe} 1-\mathrm{N} 2$ & $92.48(6)$ & O127-Mn1-N101 & $91.89(11)$ & O20-Mn1-N18 & $92.43(18)$ \\
\hline $\mathrm{O} 27-\mathrm{Fe} 1-\mathrm{N} 31$ & $85.77(7)$ & O127-Mn1-N131 & $170.14(13)$ & O20-Mn1-N31 & $89.96(17)$ \\
\hline $\mathrm{O} 46-\mathrm{Fe} 1-\mathrm{O} 47$ & $86.25(6)$ & O201-Mn1-N201 & $79.37(10)$ & O2-Mn1-O1 & $59.69(15)$ \\
\hline $\mathrm{O} 46-\mathrm{Fe} 1-\mathrm{N} 2$ & $87.20(6)$ & O201-Mn1-N101 & $92.27(10)$ & $\mathrm{O} 2-\mathrm{Mn} 1-\mathrm{N} 18$ & $108.00(15)$ \\
\hline O46-Fe1-N31 & $82.61(7)$ & O201-Mn1-N131 & $87.35(9)$ & O2-Mn1-N31 & $172.70(16$ \\
\hline $\mathrm{O} 47-\mathrm{Fe} 1-\mathrm{N} 2$ & $169.00(6)$ & N201-Mn1-N101 & $168.39(9)$ & $\mathrm{O} 1-\mathrm{Mn} 1-\mathrm{N} 18$ & $167.68(16)$ \\
\hline $\mathrm{O} 47-\mathrm{Fe} 1-\mathrm{N} 31$ & $93.22(7)$ & N201-Mn1-N131 & $93.18(12)$ & $\mathrm{O} 1-\mathrm{Mn} 1-\mathrm{N} 31$ & $113.39(16$ \\
\hline folding angle over $\mathrm{O} 46-\mathrm{O} 47$ & $10.25(10)$ & & & & \\
\hline
\end{tabular}

phenolato oxygen atoms are now coordinated in cis positions. In complex $\mathbf{1}$, the phenolato arms are more or less "forced" to occupy trans positions to allow for a JahnTeller distortion. Because the $\mathrm{d}^{5}$ high-spin iron(III) ion is not prone to the Jahn-Teller effect, the phenolato arms can occupy cis positions, thus allowing for a less distorted octahedron. A similar arrangement of cis-phenolate groups has been reported for an iron(III) complex of an analogous tripodal ligand with a tetrahydrofuran group instead of the pyridine group. ${ }^{[32]}$ The $\mathrm{Fe} 1-\mathrm{O}$ (phenolato) distances are concurrent with published values. ${ }^{[28]}$ The Fe1-N31(pyridine) and $\mathrm{Fe} 1-\mathrm{N} 2$ (amine) bond lengths are typical for $\mathrm{Fe}^{\mathrm{III}}-\mathrm{N}$ bonds. ${ }^{[28]}$ The acac ligand in complex $\mathbf{2}$ is bound asymmetrically, with the Fe1-O47 distance shorter than the Fe1O46 distance. The folding out of the chelate plane for the acac ligand is less than in complex $\mathbf{1}$, being $10.25(10)^{\circ}$.

The asymmetric unit of complex $\mathbf{5}$ contains one complex molecule and one molecule of dichloromethane. The oxyquinoline ligand in the compound [ $\mathrm{Mn}^{\mathrm{III}}(\mathrm{pppy})($ quin)] (5) allows for the pppy ligand to adopt cis positions for the phenolate arms. The Jahn-Teller axis is now located along the bonds Mn1-N201 and Mn1-N101. The Jahn-Teller distortion is clearly visible in complex $\mathbf{5}$, since the $\mathrm{Mn}-\mathrm{N}$ (amine) distance is notably larger than those in the complexes 1, 3 and 4. Also, the $\mathrm{Mn}-\mathrm{N}(\mathrm{py})$ distance is shorter in complex 5 than in each of the complexes 1, 3 and 4, because in complex $\mathbf{5}$ the pyridyl arm is not in an axial position. The equatorial plane of the coordination octahedron consists of the pyridine nitrogen, the two cis phenolate oxygen atoms and the quinolinato oxygen atom. In contrast with the folding observed for $\beta$-diketonate ligands, the manganese ion lies in the chelate plane of the 8-oxyquinoline ligand.
Compound [Mn(tbpppy)(OAc)] (9) is different from all the complexes discussed so far, given that the complex has a pppy ligand with bulky tert-butyl substituents on the phenolate groups. Furthermore, it has a bidentate acetate ligand as the second anionic ligand, binding in a significantly asymmetric fashion. The Mn1-O2 bond is rather long due to the Jahn-Teller distortion and the small bite-angle of the acetate ligand, however, since the N31-Mn1-O2 bond angle is $172.70(16)^{\circ}$, the $\mathrm{O} 2$ acetate oxygen is reasonably well aligned with the octahedral $z$-axis. The $\mathrm{O} 1$ acetate oxygen forms a regular $\mathrm{Mn1}-\mathrm{O} 1_{\mathrm{OAc}}$ bond of 1.998(4) $\AA$ but has a N18-Mn1-O1 bond angle of $167.68(18)^{\circ}$. The tbpppy ligand binding distances are in the same range as for the manganese pppy complexes. The tert-butyl substituents on the pppy ligand thus do not seem to have a significant influence on the coordination geometry of complex 9. A similar structure has been reported for copper: $\left[\mathrm{Cu}^{\mathrm{II}}(\mathrm{Htbpppy})-\right.$ (OAc)]. ${ }^{[2]}$ In this copper complex one of the two phenolate oxygen atoms is not deprotonated (but still coordinated) and the copper ion has a square-pyramidal coordination geometry with the acetate anion coordinated as a monodentate ligand.

\section{Electronic Absorption Spectroscopy}

The electronic absorption spectra for the manganese(III) complexes have been recorded in $\mathrm{CH}_{2} \mathrm{Cl}_{2}$ solution; the data are collected in Table $\mathrm{S} 1$. The electronic spectrum of $\mathbf{1}$ as a typical example is given in Figure S1. The free-ion ground term for high-spin $\mathrm{d}^{4}$ manganese(III) is ${ }^{5} \mathrm{D}$. In an octahedral ligand field this term is split in ${ }^{5} \mathrm{~T}_{2 \mathrm{~g}}$ and ${ }^{5} \mathrm{E}_{\mathrm{g}}$, and there would be one spin-allowed transition: ${ }^{5} \mathrm{~T}_{2 \mathrm{~g}} \leftarrow{ }^{5} \mathrm{E}_{\mathrm{g}} \cdot{ }^{[33]} \mathrm{How}-$ 
ever, since the complexes are all axially elongated due to the Jahn-Teller effect, the ${ }^{5} \mathrm{E}_{\mathrm{g}}$ term is further split in ${ }^{5} \mathrm{~B}_{1 \mathrm{~g}}$ and ${ }^{5} \mathrm{~A}_{1 \mathrm{~g}}$ and the ${ }^{5} \mathrm{~T}_{2 \mathrm{~g}}$ term in ${ }^{5} \mathrm{~B}_{2 \mathrm{~g}}$ and ${ }^{5} \mathrm{E}_{\mathrm{g}}$. Three spinallowed transitions would now theoretically be possible: ${ }^{5} \mathrm{~A}_{1 \mathrm{~g}} \leftarrow{ }^{5} \mathrm{~B}_{1 \mathrm{~g}},{ }^{5} \mathrm{~B}_{2 \mathrm{~g}} \leftarrow{ }^{5} \mathrm{~B}_{1 \mathrm{~g}}$ and ${ }^{5} \mathrm{E}_{\mathrm{g}} \leftarrow{ }^{5} \mathrm{~B}_{1 \mathrm{~g}}$. Only one $\mathrm{d}-\mathrm{d}$ transition could be observed for all the measured complexes in the range $625-720 \mathrm{~nm}$, tentatively attributed to ${ }^{5} \mathrm{~B}_{2 \mathrm{~g}} \leftarrow{ }^{5} \mathrm{~B}_{1 \mathrm{~g}} \cdot{ }^{[33,34]}$ Since this transition has an energy equal to $10 \mathrm{Dq},{ }^{[34]}$ the ligand-field splitting of the d-orbitals is thus directly assessable for each of the manganese complexes. The obtained values for $10 \mathrm{Dq}$ are in good agreement with reported values for related manganese(III) complexes. $^{[34]}$ Two absorptions between $350-520 \mathrm{~nm}$ are assigned as $\mathrm{L} \rightarrow \mathrm{M}$ charge-transfer transitions from a $\mathrm{p} \pi$ orbital on a phenolate oxygen to the partially-filled $\mathrm{d} \pi$ orbitals on the manganese ion, in analogy with assignments made for other $\mathrm{Mn}^{\mathrm{III}}$ complexes with phenolate ligands. ${ }^{[30,35]}$ The assignment is tentative for complex $\mathbf{5}$, since the oxyquinoline ligand also has a $\pi-\pi^{*}$ transition in this region. ${ }^{[36]}$ An absorption around $320 \mathrm{~nm}$ in complexes with a $\beta$-diketonate ligand is assigned to a $\mathrm{M} \rightarrow \mathrm{L}$ transition from the metal $\mathrm{d}_{x z}$ or $\mathrm{d}_{y z}$ orbital to the $\beta$-diketonate $\pi_{4}$ orbital (see LCAO-MO calculations for the $\pi$-energy levels of metal $\beta$-diketonates by Barnum), ${ }^{[37,38]}$ in agreement with the assignment for $\left[\mathrm{Mn}^{\mathrm{III}}(\mathrm{acac})_{3}\right]$. The observation of this transition supports the assumption that the $\beta$-diketonate ligands do not dissociate in $\mathrm{CH}_{2} \mathrm{Cl}_{2}$ solution. In the complexes $\mathbf{3}$ and $\mathbf{1 0}$ this absorption is obscured by very intense $\pi-\pi^{*}$ charge-transfer transitions, due to the phenyl rings of the dbm ligand for $\mathbf{3}$ and the nitro groups on the dnpppy ligand for 10. ${ }^{[7,39]}$ All manganese complexes show an absorption at around $230-260 \mathrm{~nm}$, which is attributed to a $\pi-\pi^{*}$ transition originating from the (substituted) pppy ligand.

The average value of $10 \mathrm{Dq}$ for each of the manganese complexes with a pppy-type tripodal ligand is: $14000 \mathrm{~cm}^{-1}$ (tbpppy) $<15400 \mathrm{~cm}^{-1}$ (pppy) $<16000 \mathrm{~cm}^{-1}$ (dnpppy). Substitution of the phenolate rings with electron-donating tert-butyl groups thus results in smaller ligand-field splitting, while substitution of the phenolate rings with electronwithdrawing nitro groups results in larger ligand-field splitting relative to the unsubstituted pppy ligand. It is thus clear that the tripodal ligands are predominantly $\pi$-donor ligands. The relative order for the values of $10 \mathrm{Dq}$ would likely be reversed if $\sigma$-type donation of the phenolate oxygens would play a more important role.

Another interesting observation is that the ligand-field splitting of the manganese(III) ion is mainly influenced by the tripodal ligand and hardly by the "secondary" ligand. This is clear from the values for $10 \mathrm{Dq}$ for complexes with the same tripodal ligand, but with different "secondary" ligands, for example the complexes 1, 3 and $\mathbf{4}$ which all have a different $\beta$-diketonate ligand but the same pppy ligand. These three complexes have very similar values for $10 \mathrm{Dq}$ $\left(15400 \mathrm{~cm}^{-1}\right.$ on average). The same observation can be made for the complexes with a tbpppy ligand (6, 9 and 8), which also all have nearly identical values for $10 \mathrm{Dq}$ $\left(14000 \mathrm{~cm}^{-1}\right.$ on average), but these values are clearly dif- ferent from the values observed for the complexes with the pppy ligand.

The electronic absorption spectra of the two iron complexes 2 and 7 have also been recorded (see the electronic spectra of $\mathbf{2}$ and 7 in Figure S2). As is expected, no absorptions due to $\mathrm{d}-\mathrm{d}$ transitions are observed for the iron complexes, since these are spin-forbidden for the high-spin $\mathrm{d}^{5}$ $\mathrm{Fe}^{\mathrm{III}}$ ion and therefore extremely weak. As for the manganese complexes, two absorptions are attributed to $\mathrm{L} \rightarrow \mathrm{M}$ charge transfer transitions. ${ }^{[7,28,39,40]}$ The absorption around $280 \mathrm{~nm}$ could be due to the $\pi_{3}-\pi_{4}$ transition of the acac ligand (as it was assigned in the manganese complexes). However, the same absorption was reported for a similar iron(III) complex with a bis(phenolate) ligand without a $\beta$ diketonate ligand; ${ }^{[39]}$ and could thus also be due to a tripodal ligand $\pi-\pi^{*}$ absorption. The transitions for complex 7 with the tert-butyl-substituted pppy ligand are shifted to lower energy, as is expected and also observed for the manganese complexes with the tbpppy ligand. Furthermore, all the absorptions for complex 7 have a lower extinction coefficient than for complex 2.

\section{Cyclic Voltammetry}

The cyclic voltammograms (CVs) of all complexes with an unsubstituted pppy ligand (complexes 1-5) are depicted in Figure 2. The peak potentials and $E_{1 / 2}$ values calculated from each of those CV measurements are listed in Table 3, as are the peak potentials obtained from the CVs of complex 10 (shown in Figure S3). All these complexes show comparable CVs: a (pseudo) reversible couple at positive potential ( $1_{\text {ox }}$ and $1_{\text {red }}$, termed "couple 1 ") and two peaks at negative potential $\left(2_{\text {red }}\right.$ and $\left.3_{\text {ox }}\right)$. The iron complex 2 differs from the Mn complexes; it displays a reversible couple at negative potential and shows an irreversible oxidation at positive potential. For each of the complexes 1-5 it was observed that if the potential is scanned beyond $+1.5 \mathrm{~V}$, an additional irreversible oxidation peak can be detected, but then no reduction peaks occur over the entire potential range on the return scan, indicating decomposition of the complex at the electrode. The CVs. of the complexes with tert-butyl-substituted pppy ligand (6-9) are provided in Figure $\mathrm{S} 4$; the peak potentials derived from these CVs. are listed in Table S2. Compounds $\mathbf{6}$ and $\mathbf{8}$ have very similar CVs. when scanned up to $1.2 \mathrm{~V}$, with one broad oxidation peak $\left(1_{\text {ox }}\right)$ and two reduction peaks $\left(1_{\text {red }}\right.$ and $\left.4_{\text {red }}\right)$ at positive potential. Only very small oxidation and reduction peaks are visible at negative potentials.

The effect of substituting the tripodal ligand with electron-donating or -withdrawing groups on the redox potentials of the manganese complexes is clearly discernible: the peak potential designated as $1_{\text {ox }}$ shifts from $0.98 \mathrm{~V}$ to $0.74 \mathrm{~V}$ to $0.67 \mathrm{~V}$ for complex 10 (dnpppy), 1 (pppy) and $\mathbf{6}$ (tbpppy), respectively. The position of redox couple 1 (complexes 1-5, and 10) thus evidently depends on the electron density on the metal centre and is therefore attributed to the metal-centred redox couple $\mathrm{Mn}^{\mathrm{III}} / \mathrm{Mn}^{\mathrm{IV}}$. The peaks at 


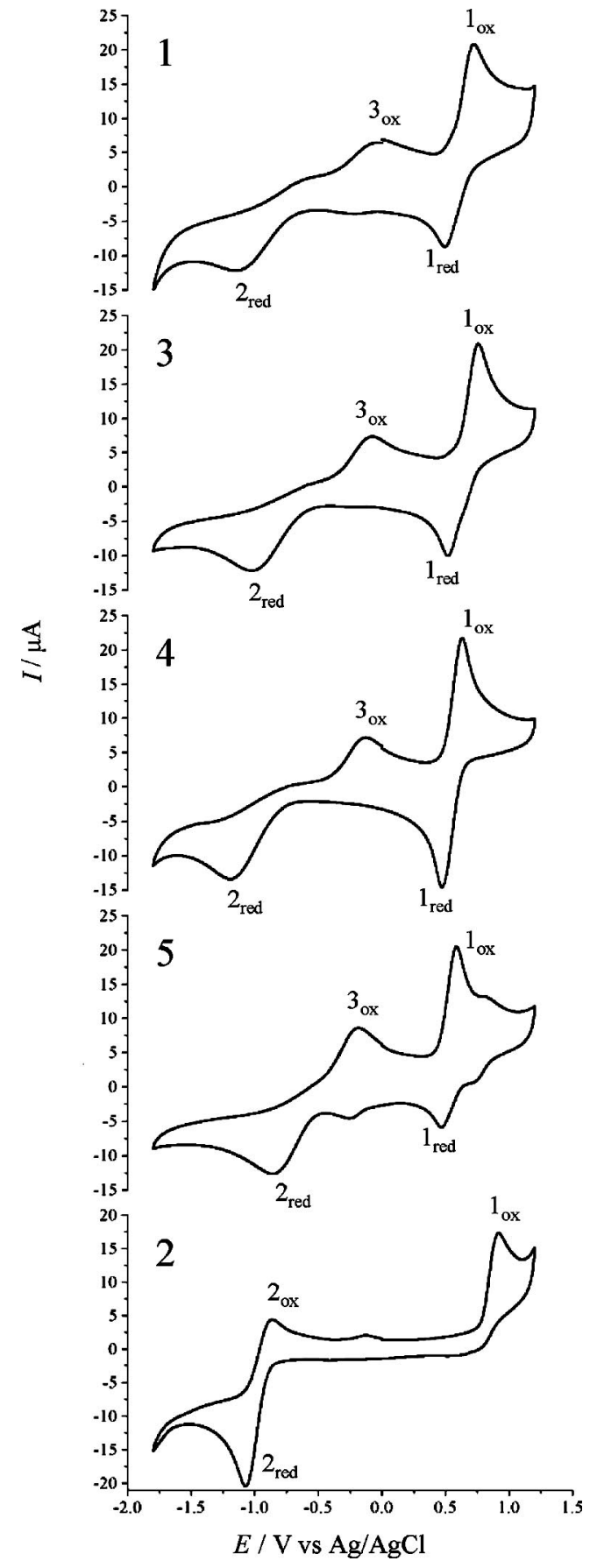

Figure 2. Cyclic voltammograms of the complexes 1-5 with pppy. Scan rate for each of the CVs was $200 \mathrm{mV} / \mathrm{s}$. negative potential are also attributed to metal-centered processes, and are assigned as the reduction to $\mathrm{Mn}^{\mathrm{II}}\left(2_{\text {red }}\right)$ and the re-oxidation to $\mathrm{Mn}^{\mathrm{III}}\left(3_{\mathrm{ox}}\right)$, in analogy with the assignment for $\left[\mathrm{Mn}^{\mathrm{III}}(\mathrm{acac})_{3}\right]^{[13]}$ The manganese complexes with a pppy ligand all show very similar CVs, regardless of the used "secondary" $\beta$-diketonate or oxyquinoline ligand. Only a small effect is visible for the complexes with the more electron-donating secondary ligands dpm (4) and quin (5): the peak potentials are shifted to slightly lower values relative to the potentials for complex $\mathbf{1}$. The ligand field data also showed this trend; the secondary ligands have little influence on the ligand-field splitting of the metal ion. Relative to $\left[\mathrm{Mn}(\mathrm{acac})_{3}\right],{ }^{[13]}$ the position of the $\mathrm{Mn}^{\mathrm{III}} /$ $\mathrm{Mn}^{\mathrm{IV}}$ couples for [Mn(pppy)(acac)] have shifted by $0.39 \mathrm{~V}$ to a lower potential. The higher oxidation state $\mathrm{Mn}^{\mathrm{IV}}$ is thus greatly stabilised in the pppy complexes, due to the very good donor capacity of the tripodal ligand. Consequently, reduction to $\mathrm{Mn}^{\mathrm{II}}$ is quite difficult for all the $\mathrm{Mn}$ complexes with a pppy ligand and especially with the donating tbpppy ligand.

A $\mathrm{Mn}^{\mathrm{III}}$ reduction peak is hardly visible for complexes 6 and $\mathbf{8}$. The appearance of "couple 1", the reversible couple at positive potential that all manganese complexes with the pppy ligand have, is not apparent for the complexes with a tbpppy ligand. The tbpppy ligand is more easily oxidised than the pppy ligand,,${ }^{[8,41]}$ and for complexes $\mathbf{6}$ and $\mathbf{8}$ the peak potentials $1_{\mathrm{ox}}, 1_{\text {red }}$ and $4_{\text {red }}$ might not be solely metalcentred. The direct oxidation/reduction potentials of the 4,6-di-tert-butylphenolate arms of the tbpppy ligand are assigned to couples 2 and $3 \cdot{ }^{[41,42]}$ Complex 8 also shows two oxidation potentials at higher potentials, but these are irreversible and cause the deposition of insoluble oxidation products on the working electrode. An assignment other than purely manganese-based for the redox processes of $\mathbf{6}$ and 8 can be that the complex is first oxidised to $\mathrm{Mn}^{\mathrm{IV}}$ and then one of the coordinated phenolate ligands is at least partially oxidised to a phenoxy radical by $\mathrm{Mn}^{\mathrm{IV}}$. Schmitt and co-workers have reported such a sequence of events for a $\mathrm{Mn}^{\mathrm{III}}$ complex with a ligand containing three phenolate groups. ${ }^{[43]}$ In the case of compound $\mathbf{6}$, the resulting species $\left[\mathrm{Mn}^{\mathrm{III}}(\mathrm{tbpppy})(\mathrm{acac})\right]$ is reduced back to the starting compound at the peak potential $4_{\text {red }}$, as shown in Scheme 3. The tiny shoulder $1_{\text {red }}$ becomes more prominent upon increase of the scan rate. This small shoulder can be attributed to the direct electrochemical reduction of the $\mathrm{Mn}^{\mathrm{IV}}$ species that is initially formed by the oxidation $1_{\text {ox }}$

Table 3. Peak potentials $E$ (in $\mathrm{V}$ vs. $\mathrm{Ag} / \mathrm{AgCl}$ ) of complexes $\mathbf{1 - 5}$ and $\mathbf{1 0}$ as determined from cyclic voltammetry. ${ }^{[\mathrm{a}]}$

\begin{tabular}{|c|c|c|c|c|c|}
\hline & $\mathrm{M}^{\mathrm{III}} / \mathrm{M}^{\mathrm{IV}}$ & & & $\mathrm{M}^{\mathrm{III}} / \mathrm{M}$ & \\
\hline Compound & $1_{\mathrm{ox}}$ & $1_{\text {red }}$ & $1 E_{1 / 2}$ & $2_{\text {red }}$ & $3_{\text {ox }}$ \\
\hline [Mn $\left.{ }^{\mathrm{III}}(\mathrm{pppy})(\mathrm{acac})\right](\mathbf{1})$ & 0.74 & 0.48 & 0.61 & -1.08 & 0 \\
\hline$\left[\mathrm{Mn}^{\mathrm{III}}(\mathrm{pppy})(\mathrm{dbm})\right](\mathbf{3})$ & 0.77 & 0.51 & 0.64 & -0.99 & -0.07 \\
\hline$\left[\mathrm{Mn}^{\mathrm{III}}(\mathrm{pppy})(\mathrm{dpm})\right](\mathbf{4})$ & 0.64 & 0.46 & 0.55 & -1.12 & -0.18 \\
\hline [Mn ${ }^{\mathrm{III}}$ (pppy)(quin)] (5) & 0.59 & 0.47 & 0.53 & -0.84 & -0.20 \\
\hline$\left[\mathrm{Fe}^{\mathrm{III}}(\right.$ pppy $\left.)(\mathrm{acac})\right](\mathbf{2})$ & 0.94 & - & - & -1.08 & -0.87 \\
\hline$\left[\mathrm{Mn}^{\mathrm{III}}(\mathrm{dnpppy})(\mathrm{acac})\right](\mathbf{1 0})$ & 0.98 & 0.8 & 0.89 & -0.38 & 0.166 \\
\hline
\end{tabular}

[a] $\mathrm{CV}$ on $1 \mathrm{~mm}$ solutions of the complex in $\mathrm{CH}_{2} \mathrm{Cl}_{2}$ under argon, Electrolyte $0.1 \mathrm{~m}\left[\mathrm{~N}(\text { butyl })_{4}\right] \mathrm{PF}$, $\mathrm{Pt}$ working electrode and $\mathrm{Ag} / \mathrm{AgCl}$ reference electrode, $E_{1 / 2}=\left(E_{\mathrm{ox}}+E_{\mathrm{red}}\right) / 2$. See Figure 2 . 
(Scheme 3). The assumed radical species $\left[\mathrm{Mn}^{\mathrm{III}}\left(\mathrm{tbpppy}^{\circ}\right)(\beta-\right.$ diketonate)] is likely to be more stable, due to delocalisation of the radical over both phenolate arms and perhaps even over the $\beta$-diketonate ligand.

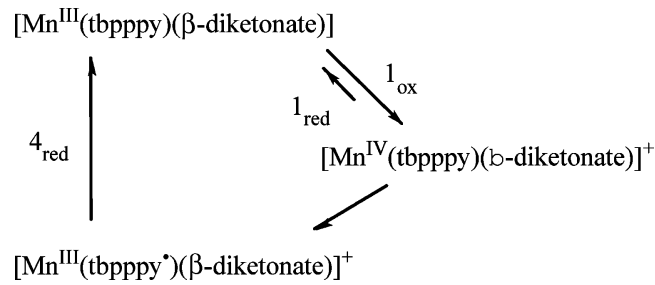

Scheme 3. Assignment of the peak potentials $1_{\text {ox }}, 1_{\text {red }}$, and $4_{\text {red }}$ in the CVs of complexes $\mathbf{6}$ and $\mathbf{8}$. See text for explanation.

Complex 9 does not show any reversible redox couple. Apparently, the secondary ligand does have an influence on stabilising higher oxidation states and the acetate ligand might just not be electron-donating enough. The peak potentials $1_{\mathrm{ox}}, 2_{\mathrm{ox}}$ and $3_{\mathrm{ox}}$ are tentatively attributable to oxidation to $\mathrm{Mn}^{\mathrm{IV}}$ and oxidations of the tbpppy ligand, but assigning the peak potentials is not unambiguous. The peaks $4_{\text {red }}$ and $5_{\text {ox }}$ are due to reduction to $\mathrm{Mn}^{\mathrm{II}}$ and then oxidation of a $\mathrm{Mn}^{\mathrm{II}}$ species.

The lower donor capacity of the ligand dnpppy results in a metal centre which is much easier to reduce, as the peak potential $2_{\text {red }}$ has shifted to a considerable more positive potential relative to the value for complex 1 (see Table 3). Consequently, redox couple 1 has shifted to a significantly more positive $E_{1 / 2}$ value.

The peak potentials of the iron complexes 2 (Figure 2) and 7 are influenced by the tripodal ligand, just as observed for the manganese complexes. The iron complex with a pppy ligand (2) does not show a reversible oxidation at positive potential, probably because the $\mathrm{Fe}^{\mathrm{IV}}$ state is less easily attained than the $\mathrm{Mn}^{\mathrm{IV}}$ state. The oxidation peak $1_{\text {ox }}$ can thus be attributed to the irreversible oxidation to $\mathrm{Fe}^{\mathrm{IV}}$ or to a ligand based oxidation. The couple $2_{\text {ox,red }}$ can probably be attributed to the $\mathrm{Fe}^{\mathrm{II}} / \mathrm{Fe}^{\mathrm{III}}$ redox couple. The iron complex with the tbpppy ligand (7) does show an oxidation and a reduction at positive potential $\left(2_{\mathrm{ox}}=1.01 \mathrm{~V}, 2_{\mathrm{red}}=0.72 \mathrm{~V}\right)$ which is tentatively assigned to the oxidation an reduction of one of the phenolate arms of the tbpppy ligand. ${ }^{[42]}$ The shoulder on the peak $2_{\text {ox }}, 1_{\text {ox }}$, might be due to either oxidation to $\mathrm{Fe}^{\mathrm{IV}}$ or ligand oxidation.

\section{Conclusions}

Several new mononuclear manganese and iron complexes of dianionic tripodal ligands have been prepared. Variation of the complexes, employing various ligand combinations show interesting variations in properties, which are useful in the study of a structure-activity relationship in oxidation catalysis.

A clear correlation between the ligand sets and the electron density of the metal centre in the complexes could be made, as was shown by the UV/Vis data and corroborated by the CV measurements. The tripodal ligands are signifi- cant $\pi$-donor ligands, and electron-withdrawing or electrondonating substituents on the phenolate arms were found to have a large influence on both the position of the $d-d$ transitions in the UV/Vis spectra and the peak potentials in the $\mathrm{CV}$ measurements. The "secondary" $\beta$-diketonate or acetate ligand does not have such a large effect on the electron density of the metal centre. Complexes with the same tripodal ligand but different $\beta$-diketonate ligands (for example 1, 3-5) were found to have very similar cyclic voltammograms and a comparable energy for the observed $\mathrm{d}-\mathrm{d}$ transition.

Especially the complexes of the tert-butyl-substituted ligand have excellent solubility in apolar solvent, necessary for their possible application in alkyd paint drying. The activity of the complexes in the autoxidation of ethyl linoleate and the proposed mechanism of the oxidation reactions are reported elsewhere. ${ }^{[29]}$

\section{Experimental Section}

General: Salicylaldehyde, 2-(aminomethyl)pyridine, 2-hydroxy-5-nitrobenzaldehyde, 2,4-di-tert-butylphenol, paraformaldehyde, 2,4pentanedione, 1,3-diphenylpropane-1,3-dione and 2,2,6,6-tetramethyl-3,5-heptanedione were purchased from Fisher Scientific and used as received. The complexes $\left[\mathrm{Mn}^{\mathrm{III}}(\mathrm{acac})_{3}\right],{ }^{[44]}\left[\mathrm{Fe}^{\mathrm{III}}-\right.$ $\left.(\mathrm{acac})_{3}\right],{ }^{[45]}\left[\mathrm{Mn}^{\mathrm{III}}(\mathrm{dpm})_{3}\right],{ }^{[46]}$ and $\left[\mathrm{Mn}^{\mathrm{III}}(\mathrm{dbm})_{3}\right],{ }^{[47]}$ were prepared according to literature procedures.

Physical Measurements: ${ }^{1} \mathrm{H}$ NMR measurements were carried out with a $200 \mathrm{MHz}$ Jeol FX-200 spectrometer equipped with a Tecmag data station. Infrared spectroscopy was done with a Perkin-Elmer 1000 FT-IR spectrophotometer, with a diamond ATR device. UV/ Vis spectra were recorded with a Varian Cary 50 spectrophotometer and elemental analyses on $\mathrm{C}, \mathrm{H}$ and $\mathrm{N}$ were performed with a Perkin-Elmer series II CHNS/O Analyzer 2400. Cyclic voltammetry measurements were performed on $\mathrm{CH}_{2} \mathrm{Cl}_{2}$ solutions with an Autolab PGSTAT 10 potentiostat using an $\mathrm{Ag} / \mathrm{AgCl}$ reference electrode, a Pt working electrode and a Pt counter electrode with $0.1 \mathrm{M}$ tetrabutylammonium hexafluorophosphate as an electrolyte. Ferrocene was measured as a reference under the exact same conditions as the complexes; $E_{1 / 2}=0.45 \mathrm{~V}$ vs. $\mathrm{Ag} / \mathrm{AgCl}$.

Ligand Synthesis: 2-[(2-Hydroxybenzyl)aminomethyl]pyridine. ${ }^{[26]}$ This compound was obtained as a light yellow needles in $67 \%$ yield $(2.86 \mathrm{~g})$ after column purification, following a literature procedure. In a different batch, the crude product was obtained as a yellow oil (the column purification was omitted) in $80 \%$ yield $(8.53 \mathrm{~g})$. This oil is sufficiently pure for further reactions. ${ }^{1} \mathrm{H} \mathrm{NMR}\left(\mathrm{CDCl}_{3}\right)$ : (yellow needles): $\delta=8.58$ (m, $1 \mathrm{H}$, py), 7.67 (dt, $1 \mathrm{H}, \mathrm{py}), 7.19$ (m, $2 \mathrm{H}$, py), 7.25-6.78 (m, $4 \mathrm{H}$, aryl), 4.02 (s, $2 \mathrm{H}, \mathrm{N}-\mathrm{CH}_{2}$-phenol), 3.93 (s, $2 \mathrm{H}, \mathrm{N}-\mathrm{CH}_{2}$-py) ppm. IR (neat): $\tilde{v}=3265,2948,2916$, 2860, 1593, 1568, 1481, 1464, 1456, 1428, 1354, 1320, 1279, 1278, 1258, 1218, 1187, 1149, 1108, 1088, 1069, 1045, 1038, 984, 979, $968,923,863,845,810,794,746,624,564,543,508,472,460,438$, $404 \mathrm{~cm}^{-1}$.

2-[Bis(2-hydroxybenzyl)aminomethyl]pyridine $\quad\left(\mathbf{H}_{2} \mathbf{p p p y}\right) \mathbf{:}^{[26]}$ This compound was synthesised according to literature, and was obtained as a white powder in $27 \%$ yield $(1.75 \mathrm{~g}) .{ }^{1} \mathrm{H}$ NMR $\left(\mathrm{CDCl}_{3}\right)$ : $\delta=8.67$ (d, $1 \mathrm{H}$, py), $7.73(\mathrm{dt}, 1 \mathrm{H}, \mathrm{py}), 7.30$ (m, $1 \mathrm{H}$, py), 7.237.13 (m, $3 \mathrm{H}$, aryl and py), 7.09 (dd, $2 \mathrm{H}$, aryl), 6.90-6.76 (m, $4 \mathrm{H}$, aryl), 3.92 (s, $2 \mathrm{H}, \mathrm{CH}_{2}$-Py), 3.85 (s, $4 \mathrm{H}, \mathrm{CH}_{2}$-phenol) ppm. IR (neat): $\tilde{v}=3014,2924,2825,1585,1490,1431,1379,1281,1250$, 
1188, 1149, 1090, 1040, 1004, 977, 956, 934, 868, 852,807, 746, $630,478 \mathrm{~cm}^{-1}$.

2-[Bis(2-hydroxy-5-nitrobenzyl)aminomethyl]pyridine $\quad\left(\mathbf{H}_{2} \mathrm{dnpppy}\right)$ : The intermediate compound 2-[(2-hydroxy-5-nitrobenzyl)aminomethyl]pyridine was prepared according to the literature method ${ }^{[26]}$ and the obtained yellow powder was used without further purification for the synthesis of $\mathrm{H}_{2}$ dnpppy. $\mathrm{H}_{2}$ dnpppy was prepared according to the method for $\mathrm{H}_{2}$ pppy, but column purification of the final product proved to be unnecessary: washing the crude yellow powder with $\mathrm{CHCl}_{3}$ resulted in the pure ligand in $14 \%(0.45 \mathrm{~g})$ yield. ${ }^{1} \mathrm{H}$ NMR ([D $]$ acetone): $\delta=8.68(\mathrm{~d}, 1 \mathrm{H}, \mathrm{OH}), 8.17(\mathrm{~d}, 2 \mathrm{H}$, aryl), 8.08 (d, $2 \mathrm{H}$, aryl), 8.01 (d, $1 \mathrm{H}$, py), 7.93 (t, $1 \mathrm{H}$, aryl), 7.46 (t, $2 \mathrm{H}$, py), 6.93 [d, $2 \mathrm{H}$, ar (ortho to $\mathrm{OH}$ )], 4.13 (s, $2 \mathrm{H}$, py- $\mathrm{CH}_{2}$ ), 4.07 (s, $\left.4 \mathrm{H}, \operatorname{ar}-\mathrm{CH}_{2}\right) \mathrm{ppm}$. IR (neat): $\tilde{v}=3100(\mathrm{vb}, \mathrm{OH}), 2548(\mathrm{vb})$, 1621, 1600, 1586, 1521, 1505, 1486, 1465, 1433, 1393, 1332, 1295, 1260, 1243, 1216, 1178, 1152, 1093, 1048, 1012, 977, 940, 908, 867, $840,824,750,737,724,667,654,636,620,557,524,495,477,452$, $412,367,337 \mathrm{~cm}^{-1}$.

2-[Bis(2-hydroxy-3,5-di-tert-butylbenzyl)aminomethyl]pyridine $\left(\mathbf{H}_{2}\right.$ tbpppy): ${ }^{[2]}$ This ligand has been prepared according to a literature procedure, however, doubling the concentration of the reagents, the quantity of the reagents and the reaction time resulted in a higher yield than previously reported. A white powder was obtained in $71 \%(7.73 \mathrm{~g})$ yield. ${ }^{1} \mathrm{H}$ NMR: $\delta=10.51(\mathrm{~s}, 2 \mathrm{H}, \mathrm{OH})$, 8.69 (d, $1 \mathrm{H}$, py), 7.21 (d, $2 \mathrm{H}$, aryl), 7.14 (d, $1 \mathrm{H}$, py), 6.94 (d, 2 $\mathrm{H}$, aryl), 3.84 (s, $2 \mathrm{H}$, py- $\left.\mathrm{CH}_{2}\right), 3.78\left(\mathrm{~m}, 4 \mathrm{H}, \mathrm{Ar}-\mathrm{CH}_{2}\right), 1.60[\mathrm{~m}$, $\left.18 \mathrm{H},\left(\mathrm{CH}_{3}\right)_{3} \mathrm{C}\right], 1.24\left[\mathrm{~m}, 18 \mathrm{H},\left(\mathrm{CH}_{3}\right)_{3} \mathrm{C}\right] \mathrm{ppm}$. IR (neat): $\tilde{v}=3100$ (OH) 2952 (CHalif), 2867, 1598, 1571, 1482, 1435, 1418, 1362, 12.94, 1231, 1204, 1164, 1122, 1093, 1050, 1004, 976, 941, 876, 863, $822,800,760,732,686,668,648 \mathrm{~cm}^{-1}$

Complex Synthesis: The preparation of the complex [Mn ${ }^{\mathrm{III}}(\mathrm{pppy})-$ (acac)] is given as an example for the general method used to obtain complexes of the type [M(tripod)( $\beta$-diketonate)].

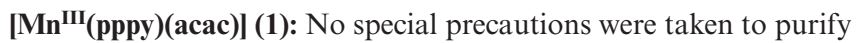
solvents and the reaction was performed in air. $1 \mathrm{mmol}(0.352 \mathrm{~g})$ of $\left[\mathrm{Mn}(\mathrm{acac})_{3}\right]$ was dissolved in $20 \mathrm{~mL}$ of $\mathrm{CH}_{2} \mathrm{Cl}_{2}$ in an erlenmeyer flask. $1 \mathrm{mmol}(0.320 \mathrm{~g})$ of $\mathrm{H}_{2}$ pppy was dissolved in $20 \mathrm{~mL}$ of $\mathrm{CH}_{2} \mathrm{Cl}_{2}$ in another Erlenmeyer flask, with the addition of 2 equiv. $(273 \mu \mathrm{L})$ of triethylamine. Then, the ligand solution was added to the $\left[\mathrm{Mn}(\mathrm{acac})_{3}\right]$ solution while stirring. The color of the [Mn$\left.(\mathrm{acac})_{3}\right]$ solution changed slightly from brown to brown/red. The reaction mixture was left stirring at room temperature, typically for $18 \mathrm{~h}$. Then the solvent was evaporated and the residue was taken up in $20 \mathrm{~mL}$ of acetone. Addition of an equal volume of $\mathrm{H}_{2} \mathrm{O}$ precipitated the complex as a brown powder, which was dried in vacuo over $\mathrm{P}_{2} \mathrm{O}_{5}$. Yield $45 \mathrm{mg}(10 \%)$. Black single crystals were obtained by solvent diffusion of $n$-hexane into a solution of the complex in $\mathrm{CH}_{2} \mathrm{Cl}_{2}$. $\mathrm{C}_{25} \mathrm{H}_{25} \mathrm{MnN}_{2} \mathrm{O}_{4}$ (472.42): calcd. C 63.56, H 5.33, N 5.93; found C 62.96, H 5.40, N 5.99. IR (neat): $\tilde{v}=3065,1654,1591$, 1540, 1516, 1476, 1448, 1424, 1373, 1346, 1268, 1226, 1194, 1148, 1112, 1096, 1048, 1019, 967, 922, 887, 874, 804, 766, 749, 730, 716, $665,648,628,610,564,524,492,478,428,405,380,316 \mathrm{~cm}^{-1}$.

[Fe'II(pppy)(acac)] (2): This complex was synthesised according to the general method. Yield $60 \mathrm{mg}(13 \%)$ of a red/brown powder. Single crystals were obtained by solvent diffusion of hexane into a solution of the complex in $\mathrm{CH}_{2} \mathrm{Cl}_{2}$. $\mathrm{C}_{25} \mathrm{H}_{25} \mathrm{FeN}_{2} \mathrm{O}_{4}$ (473.33): calcd. C 63.44, H 5.32, N 5.92; found C 62.39, H 5.40, N 5.98. IR (neat): $\tilde{v}=3067,2915,1592,1576,1558,1516,1476,1456,1445,1418$, 1374, 1283, 1266, 1193, 1155, 1112, 1088, 1038, 1022, 968, 928, $884,841,792,752,731,647,633,606,550,511,479,427 \mathrm{~cm}^{-1}$.

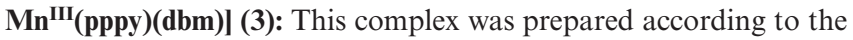
general method, starting with $0.5 \mathrm{mmol}(0.362 \mathrm{~g})\left[\mathrm{Mn}^{\mathrm{III}}(\mathrm{dbm})_{3}\right]$ and $0.5 \mathrm{mmol}(0.160 \mathrm{~g}) \mathrm{H}_{2}$ pppy. The brown powder that was initially obtained contained $\mathrm{Hdbm}$ as an impurity and needed to be recrystallised twice from $\mathrm{CH}_{2} \mathrm{Cl}_{2} / n$-hexane to obtain pure compound 3. The yield of the recrystallised brown powder was $120 \mathrm{mg}$ $(40 \%) . \mathrm{C}_{35} \mathrm{H}_{29} \mathrm{MnN}_{2} \mathrm{O}_{4}$ (596.56): calcd. C 70.47, H 4.90, N 4.70; found $\mathrm{C}$ 69.21, H 4.92, N 4.85. IR (neat): $\tilde{v} \approx 3050$ (arom. C-H), 1592, 1550, 1513, 1476, 1449, 1379, 1334, 1292, 1274, 1224, 1180, 1162, 1070, 1056, 1019, 1000, 965, 938, 927, 887, 876, 850, 808, $778,750,736,724,695,680,639,618,610,566,530,489,476,422$, $389,343,324$

[Mn'I(pppy)(dpm)] (4): This complex has been prepared following two different methods:

A: According to the general method, starting from $0.5 \mathrm{mmol}$ $(0.302 \mathrm{~g})\left[\mathrm{Mn}^{\mathrm{III}}(\mathrm{dpm})_{3}\right]$ and $0.5 \mathrm{mmol}(0.160 \mathrm{~g}) \mathrm{H}_{2}$ pppy, no triethylamine was added in this synthesis. Black crystalline material was obtained from the acetone solution, after addition of $\mathrm{H}_{2} \mathrm{O}$. Another batch of crystalline material was obtained from this solution after standing overnight at $+4{ }^{\circ} \mathrm{C}$. Total yield $92 \mathrm{mg}(33 \%)$. Single crystals suitable for $\mathrm{X}$-ray diffraction were obtained from letting an acetone $/ \mathrm{H}_{2} \mathrm{O}$ solution of the complex stand at $+4{ }^{\circ} \mathrm{C}$.

B: To a solution of $0.5 \mathrm{mmol}(0.160 \mathrm{~g}) \mathrm{H}_{2}$ pppy and $1 \mathrm{mmol}$ $(140 \mu \mathrm{L})$ triethylamine in $20 \mathrm{~mL}$ of $\mathrm{MeOH}$ was added a solution of $\left[\mathrm{Mn}^{\mathrm{II}}\left(\mathrm{H}_{2} \mathrm{O}\right)_{6}\right]\left(\mathrm{ClO}_{4}\right)_{2}$ in $10 \mathrm{~mL}$ of $\mathrm{MeOH}$, while stirring. Caution! Perchlorate complexes are hazardous and potentially explosive! The resulting reaction mixture immediately turned brown. After $10 \mathrm{~min}$ of stirring, a solution of $0.5 \mathrm{mmol}(92 \mathrm{mg}) \mathrm{Hdpm}$ and $0.5 \mathrm{mmol}$ $(70 \mu \mathrm{L})$ triethylamine in $10 \mathrm{~mL}$ of $\mathrm{MeOH}$ was added. Stirring was continued for $1 \mathrm{~h}$. Then, the reaction mixture was concentrated on a rotary evaporator to approximately $15 \mathrm{~mL}$. While stirring the concentrated solution, water was slowly added until a brown powder precipitated. The water/MeOH mixture was left stirring for an additional $10 \mathrm{~min}$, and the brown powder was collected by filtration. The powder was dried in vacuo over $\mathrm{P}_{2} \mathrm{O}_{5}$ for $48 \mathrm{~h}$. This was the desired product in $74 \%(0.2 \mathrm{~g})$ yield. $\mathrm{C}_{31} \mathrm{H}_{37} \mathrm{MnN}_{2} \mathrm{O}_{4}$ (556.58): calcd. C 66.90, H 6.70, N 5.03; found C 66.79, H 6.72, N 4.95. IR (neat): $\tilde{v}=2962,1597,1569,1528,1498,1477,1451,1384$, 1356, 1298, 1265, 1225, 1180, 1134, 1110, 1018, 964, 874, 790, 754, $737,643,628,528,492,475,460,418,390 \mathrm{~cm}^{-1}$.

[Mn'II(pppy)(quin)] (5): This complex was prepared according to method B for complex 4. Yield 56\% (145 mg). Single crystals (fine brown needles) suitable for X-ray diffraction were obtained by letting a solution of the compound in $\mathrm{CH}_{2} \mathrm{Cl}_{2} / n$-hexane (1:1) stand at $-20{ }^{\circ} \mathrm{C} . \mathrm{C}_{29} \mathrm{H}_{24} \mathrm{MnN}_{3} \mathrm{O}_{3} \cdot\left(\mathrm{CH}_{2} \mathrm{Cl}_{2}\right)_{0.3}$ (542.94): calcd. C 64.82, $\mathrm{H}$ 4.57, N 7.74; found C 64.99, H 4.55, N 7.84. IR (neat): $\tilde{v}=3044$, 2836, 1613, 1593, 1572, 1496, 1464, 1448, 1440, 1386, 1373, 1322, 1291, 1266, 1230, 1190, 1160, 1106, 1059, 1037, 992, 967, 932, 882, $825,804,792,752,723,696,647,631,599,527,485,424,396 \mathrm{~cm}^{-1}$.

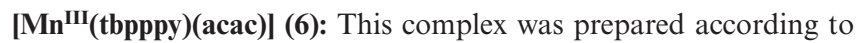
the general method. A brown powder was obtained. The yield was $60 \%$ (240 mg). $\mathrm{C}_{41} \mathrm{H}_{57} \mathrm{MnN}_{2} \mathrm{O}_{4} \cdot 2 \mathrm{H}_{2} \mathrm{O}$ (732.88): calcd. C $67.19, \mathrm{H}$ 8.39, N 3.82; found C 67.78, H 8.39, N 3.86. IR (neat): $\tilde{v}=2953$ (CHalif), 1654, 1590, 1516, 1472, 1440, 1414, 1386, 1361, 1304, 1256, 1238, 1203, 1168, 1130, 1094, 1050, 1016, 976, 914, 875, 837, $668,645,611,568,499,451,420,401 \mathrm{~cm}^{-1}$.

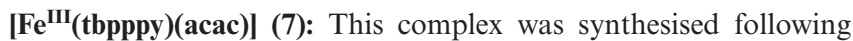
the general procedure, using $\left[\mathrm{Fe}(\mathrm{acac})_{3}\right]$ and $\mathrm{H}_{2}$ tbpppy. The yield was $16 \%(55 \mathrm{mg})$ of a purple powder. $\mathrm{C}_{41} \mathrm{H}_{57} \mathrm{FeN}_{2} \mathrm{O}_{4}$ (697.76): calcd. C 70.58, H 8.23, N 4.01; found C 69.99, H 8.85, N 4.00. IR (neat): $\tilde{v}=2951$ (CHalif), 1654, 1590, 1522, 1481, 1436, 1415, 1386, 1361, 1295, 1269, 1232, 1202, 1166, 1129, 1051, 1008, 974, 930, $877,861,836,800,754,666,648,608,545,506,478,432,400 \mathrm{~cm}^{-1}$. 
Table 4. Crystallographic data and details of the structure determinations for complexes 1-5 and $\mathbf{9 .}$

\begin{tabular}{|c|c|c|c|c|c|c|}
\hline & 1 & 2 & 3 & 4 & 5 & 9 \\
\hline Formula & $\mathrm{C}_{25} \mathrm{H}_{25} \mathrm{MnN}_{2} \mathrm{O}_{4}$ & $\mathrm{C}_{25} \mathrm{H}_{25} \mathrm{FeN}_{2} \mathrm{O}_{4}$ & $\mathrm{C}_{35} \mathrm{H}_{29} \mathrm{MnN}_{2} \mathrm{O}_{4}$ & $\mathrm{C}_{31} \mathrm{H}_{37} \mathrm{MnN}_{2} \mathrm{O}_{4}$ & $\mathrm{C}_{29} \mathrm{H}_{24} \mathrm{MnN}_{3} \mathrm{O}_{3} \cdot \mathrm{CH}_{2} \mathrm{Cl}_{2}$ & $\mathrm{C}_{38} \mathrm{H}_{53} \mathrm{MnN}_{2} \mathrm{O}_{4}$ \\
\hline$F w$ & 472.4 & 473.3 & 596.5 & 556.6 & 602.4 & 656.8 \\
\hline Space group & $P 2_{1} / c$ & $C 2 / c$ & $P 2_{1} 2_{1} 2_{1}$ & $P \overline{1}$ & $P 2_{1} / c$ & $P 2_{1} / c$ \\
\hline$T[\mathrm{~K}]$ & 150 & 150 & 150 & 150 & 150 & 173 \\
\hline$a[\AA]$ & $8.0774(1)$ & $22.4132(5)$ & $13.8331(10)$ & $12.151(11)$ & $14.8062(10)$ & $16.035(4)$ \\
\hline$b[\AA]$ & $29.1222(3)$ & $6.9219(1)$ & $13.8434(10)$ & $14.049(18)$ & $12.4055(10)$ & $13.233(5)$ \\
\hline$c[\AA]$ & $20.0292(2)$ & $30.6673(6)$ & $14.6932(10)$ & $17.291(7)$ & $20.5767(10)$ & $18.957(3)$ \\
\hline$\alpha\left[^{\circ}\right]$ & 90 & 90 & 90 & $85.79(7)$ & 90 & 90 \\
\hline$\beta\left[^{\circ}\right]$ & $106.4840(10)$ & $109.6502(8)$ & 90 & $86.16(6)$ & $133.708(3)$ & $111.09(2)$ \\
\hline$\gamma\left[{ }^{\circ}\right]$ & 90 & 90 & 90 & $77.09(10)$ & 90 & 90 \\
\hline$V\left[\AA^{3}\right]$ & $4517.85(9)$ & $4480.71(15)$ & $2813.7(3)$ & $2866(5)$ & 2732.1(3) & 3753.1(19) \\
\hline$D_{\text {calcd. }}\left[\mathrm{g} \mathrm{cm}^{-3}\right]$ & 1.389 & 1.403 & $1.4082(2)$ & $1.290(2)$ & $1.4645(2)$ & $1.1623(6)$ \\
\hline$Z$ & 8 & 8 & 4 & 4 & 4 & 4 \\
\hline Crystal size [mm] & $0.15 \times 0.21 \times 0.36$ & $0.06 \times 0.15 \times 0.54$ & $0.20 \times 0.20 \times 0.25$ & $0.05 \times 0.06 \times 0.51$ & $0.03 \times 0.10 \times 0.24$ & $0.06 \times 0.17 \times 0.20$ \\
\hline $2 \theta_{\max }\left[{ }^{\circ}\right]$ & 55 & 55 & 55 & 45 & 55 & 50.5 \\
\hline Unique data & 10249 & 5020 & 6455 & 7468 & 6239 & 6717 \\
\hline$R^{[\mathrm{a}]}$ & 0.0377 & 0.0384 & 0.0231 & 0.0597 & 0.0494 & 0.0819 \\
\hline$w R_{2}^{[\mathrm{b}]}$ & 0.0928 & 0.0849 & 0.0597 & 0.1257 & 0.1244 & 0.1806 \\
\hline$R$ (int.) & 0.060 & 0.050 & 0.046 & 0.104 & 0.078 & 0.199 \\
\hline$\Delta \rho_{\min }, \Delta \rho_{\max }\left[\mathrm{e} \AA^{-3}\right]$ & $-0.32,0.31$ & $-0.36,0.33$ & $-0.29,0.19$ & $-0.39,0.44$ & $-0.80,0.89$ & $-0.36,0.92$ \\
\hline
\end{tabular}

[a] $R=\Sigma\left(|| F_{\mathrm{o}}|-| F_{\mathrm{c}} \mid\right) / \Sigma\left|F_{\mathrm{o}}\right| \cdot[\mathrm{b}] w R_{2}=\left\{\Sigma\left[w\left(F_{\mathrm{o}}{ }^{2}-F_{\mathrm{c}}{ }^{2}\right)^{2}\right] / \Sigma\left[w\left(F_{\mathrm{o}}{ }^{2}\right)^{2}\right]\right\}^{1 / 2}$.

[Mn $\left.{ }^{\text {III }}(\mathbf{t b p p p y})(\mathbf{d p m})\right]$ (8): This complex was prepared according to the general method, starting from $0.5 \mathrm{mmol}(0.30 \mathrm{~g})\left[\mathrm{Mn}(\mathrm{dpm})_{3}\right]$ and $0.5 \mathrm{mmol}(0.272 \mathrm{~g}) \mathrm{H}_{2}$ tbpppy, with $\mathrm{CHCl}_{3}$ as a solvent and a reaction time of $48 \mathrm{~h}$. A black/brown micro-crystalline powder was obtained in $90 \%\left(0.35\right.$ g) yield. $\mathrm{C}_{47} \mathrm{H}_{69} \mathrm{MnN}_{2} \mathrm{O}_{4}$ (781.01): calcd. $\mathrm{C}$ 72.28, H 8.90, N 3.59; found C 71.21, H 9.35, N 3.49. IR (neat): $\tilde{v}$ $=2951,1589,1570,1526,1496,1471,1437,1400,1386,1360,1306$, $1279,1240,1220,1202,1167,1130,1087,1047,1016,976,932$, $914,869,840,808,788,775,761,752,644,613,568,558,529,499$, $475,452,397,368 \mathrm{~cm}^{-1}$.

[Mn'IIt(tbppy)(OAc)] (9): $0.20 \mathrm{~g}(0.37 \mathrm{mmol}) \mathrm{H}_{2}$ tbpppy, together with $74 \mathrm{mg}(0.73 \mathrm{mmol})$ triethylamine, was dissolved in $15 \mathrm{~mL}$ $\mathrm{CH}_{2} \mathrm{Cl}_{2}$ and added to $0.09 \mathrm{~g}(0.37 \mathrm{mmol})\left[\mathrm{Mn}(\mathrm{OAc})_{3}\right] \cdot 2 \mathrm{H}_{2} \mathrm{O}$, dissolved in $5 \mathrm{~mL} \mathrm{CH} \mathrm{Cl}_{2}$. After $24 \mathrm{~h}$ of stirring a precipitate could be collected by filtration. A purple powder was obtained in $26 \%$ $(63 \mathrm{mg})$ yield. Single crystals were obtained by solvent diffusion of hexane into a solution of the complex in $\mathrm{CH}_{2} \mathrm{Cl}_{2} . \mathrm{C}_{38} \mathrm{H}_{53} \mathrm{MnN}_{2} \mathrm{O}_{4}$ (656.78): calcd. C 69.49, H 8.13, N 4.27; found C 68.98, H 8.39, N 4.29. IR (neat): $\tilde{v}=2950,1604,1578,1478,1439,1413,1390,1362$, 1332, 1309, 1276, 1239, 1204, 1169, 1129, 1080, 1048, 1015, 975, $914,877,840,808,778,762,752,729,695,668,656,643,614,575$, $559,500,454,402,352 \mathrm{~cm}^{-1}$.

[Mn'IIInpppy)(acac)] (10): This compound was prepared according to the general procedure. A greenish brown powder was obtained, yield $29 \%$ (81 mg). $\mathrm{C}_{25} \mathrm{H}_{23} \mathrm{MnN}_{4} \mathrm{O}_{8}$ (562.41): calcd. C 53.39, $\mathrm{H}$ 4.12, N 9.96; found C 52.62, H 4.10, N 10.09. IR (neat): $\tilde{v}=1600$, 1571, 1474, 1438, 1331, 1282, 1184, 1090, 1018, 943, 924, 870, 832, 782, 756, 738, 664, 564, 510, $477 \mathrm{~cm}^{-1}$.

X-ray Crystallographic Analysis and Data Collection: The crystallographic information and data concerning the determination of the structures are given in Table 4. Intensity data for single crystals of 1-5 and 9 were collected using Mo- $K_{\alpha}$ radiation $(\lambda=0.71073 \AA)$ with a Nonius KappaCCD diffractometer. The structures (1-5) were solved with DIRDIF99 (1-3) or SHELXS86 (4-5). The programs PLATON/MULABS, PLATON/DELABS, SADABS, EVALCCD and DENZO were used for absorption correction and data reduction, respectively. SHELXL97 was used for the leastsquares structure refinement. All non-hydrogens were refined with anisotropic displacement parameters. All hydrogens were placed at calculated positions and were refined riding on their parent atoms. Structure 4 contains small solvent accessible voids of 37 and $70 \AA^{3}$. The contribution of the disordered solvent of crystallization in the voids was taken into account in the structure factor calculation with the PLATON/SQUEEZE routine. Geometric calculations and molecular graphics were performed with the PLATON package. ${ }^{[48]}$

CCDC-651099 (for 1), -651100 (for 2), -651101 (for 3), -651102 (for 4), -651103 (for 5) and -651578 (for 9) contain the supplementary crystallographic data for this paper. These data can be obtained free of charge from The Cambridge Crystallographic Data Centre via www.ccdc.cam.ac.uk/data_request/cif.

Supporting Information (see also the footnote on the first page of this article): Electronic spectra and data, cyclic voltammograms and electrochemical data.

\section{Acknowledgments}

This work was carried out as part of the SENTER/Innovation Oriented Research Program on Heavy Metals (IOP), sponsored by the Dutch Ministry of Economic Affairs (project no. IZW99241c). The crystallography was supported by the Nederlandse Organisatie voor Wetenschappelijk Onderzoek, Chemische Wetenschappen (NWO-CW) (A. L. S., A. M. M., D. M. T.).

[1] J. A. Halfen, B. A. Jazdzewski, S. Mahapatra, L. M. Berreau, E. C. Wilkinson, L. Que, W. B. Tolman, J. Am. Chem. Soc. 1997, 119, 8217-8227.

[2] Y. Shimazaki, S. Huth, A. Odani, O. Yamauchi, Angew. Chem. Int. Ed. 2000, 39, 1666.

[3] A. Sokolowski, H. Leutbecher, T. Weyhermuller, R. Schnepf, E. Both, E. Bill, P. Hildebrandt, K. Wieghardt, J. Biol. Inorg. Chem. 1997, 2, 444-453.

[4] F. Thomas, Eur. J. Inorg. Chem. 2007, 2379-2404.

[5] Y. D. Wang, T. D. P. Stack, J. Am. Chem. Soc. 1996, 118, 13097-13098.

[6] C. J. Carrano, M. W. Carrano, K. Sharma, G. Backes, J. Sanders-Loehr, Inorg. Chem. 1990, 29, 1865-1870.

[7] M. Merkel, F. K. Muller, B. Krebs, Inorg. Chim. Acta 2002, $337,308-316$. 
[8] N. Reddig, D. Pursche, B. Krebs, A. Rompel, Inorg. Chim. Acta 2004, 357, 2703-2712.

[9] M. U. Triller, D. Pursche, W. Y. Hsieh, V. L. Pecoraro, A. Rompel, B. Krebs, Inorg. Chem. 2003, 42, 6274-6283.

[10] M. Velusamy, R. Mayilmurugan, M. Palaniandavar, Inorg. Chem. 2004, 43, 6284-6293.

[11] S. P. Yan, X. Y. Pan, L. F. Taylor, J. H. Zhang, C. J. Oconnor, D. Britton, O. P. Anderson, L. Que, Inorg. Chim. Acta 1996, 243, 1-8.

[12] A. R. Brash, J. Biol. Chem. 1999, 274, 23679-23682.

[13] R. van Gorkum, E. Bouwman, J. Reedijk, Inorg. Chem. 2004, 43, 2456-2458.

[14] S. T. Warzeska, M. Zonneveld, R. van Gorkum, W. J. Muizebelt, E. Bouwman, J. Reedijk, Prog. Org. Coat. 2002, 44, 243248.

[15] J.-Z. Wu, E. Bouwman, J. Reedijk, Prog. Org. Coat. 2004, 49, $103-108$.

[16] T. Brock, W. Stopford, J. Environ. Monit. 2003, 5, 71N-76N.

[17] J. R. Bucher, J. R. Hailey, J. R. Roycroft, J. K. Haseman, R. C. Sills, S. L. Grumbein, P. W. Mellick, B. J. Chou, Toxicol. Sci. 1999, 49, 56-67.

[18] D. Lison, M. De Boeck, V. Verougstraete, M. Kirsch-Volders, Occup. Environ. Med. 2001, 58, 619-625.

[19] W. Stopford, J. Turner, D. Cappellini, T. Brock, J. Environ. Monit. 2003, 5, 675-680.

[20] C. R. Goldsmith, R. T. Jonas, T. D. P. Stack, J. Am. Chem. Soc. 2002, 124, 83-96.

[21] N. Lehnert, R. Y. N. Ho, L. Que, E. I. Solomon, J. Am. Chem. Soc. 2001, 123, 12802-12816.

[22] S. Ogo, S. Wada, Y. Watanabe, M. Iwase, A. Wada, M. Harata, K. Jitsukawa, H. Masuda, H. Einaga, Angew. Chem. Int. Ed. 1998, 37, 2102-2104

[23] S. Ogo, R. Yamahara, M. Roach, T. Suenobu, M. Aki, T. Ogura, T. Kitagawa, H. Masuda, S. Fukuzumi, Y. Watanabe, Inorg. Chem. 2002, 41, 5513-5520.

[24] Z. O. Oyman, W. Ming, R. van der Linde, R. van Gorkum, E. Bouwman, Polymer 2005, 46, 1731-1738.

[25] R. E. Boomgaard, H. Schier, E. J. J. Kirchner, R. P. Klaasen, F. Hartl, R. P. C. Van der Leeuw, F. J. A. D. Bakkeren, Akzo Nobel N. V., World WO3029371, 2003.

[26] Y. L. Tong, Y. Yan, E. S. H. Chan, Q. C. Yang, T. C. W. Mak, D. K. P. Ng, J. Chem. Soc. Dalton Trans. 1998, 3057-3064.

[27] R. Uma, R. Viswanathan, M. Palaniandavar, M. Lakshminarayanan, J. Chem. Soc. Dalton Trans. 1994, 1219-1226.

[28] R. Viswanathan, M. Palaniandavar, T. Balasubramanian, T. P. Muthiah, Inorg. Chem. 1998, 37, 2943-2951.
[29] R. van Gorkum, J. Berding, D. M. Tooke, A. L. Spek, J. Reedijk, E. Bouwman, J. Catal. 2007, 252, 110-118.

[30] M. Hirotsu, M. Kojima, W. Mori, Y. Yoshikawa, Bull. Chem. Soc. Jpn. 1998, 71, 2873-2884.

[31] J. Burgess, in Comprehensive Coordination Chemistry, Vol. 2 (Ed.: G. Wilkinson), Pergamon Press, Oxford, 1987, p. 370.

[32] E. Safaei, T. Weyhermüller, E. Bothe, K. Wieghardt, P. Chaudhuri, Eur. J. Inorg. Chem. 2007, 2334-2344.

[33] A. B. P. Lever, in Inorganic Electronic Spectroscopy, 2nd ed., Elsevier, New York, 1986, p. 435.

[34] Y. Murakami, K. Sakata, K. Harada, Y. Matsuda, Bull. Chem. Soc. Jpn. 1974, 47, 3021-3024.

[35] A. Neves, S. M. D. Erthal, I. Vencato, A. S. Ceccato, Y. P. Mascarenhas, O. R. Nascimento, M. Horner, A. A. Batista, Inorg. Chem. 1992, 31, 4749-4755.

[36] M. M. Ray, J. N. Adhya, D. Biswas, S. N. Poddar, Aust. J. Chem. 1966, 19, 1737.

[37] D. W. Barnum, J. Inorg. Nucl. Chem. 1961, 22, 183-191.

[38] D. W. Barnum, J. Inorg. Nucl. Chem. 1961, 21, 221-237.

[39] M. Velusamy, M. Palaniandavar, R. S. Gopalan, G. U. Kulkarni, Inorg. Chem. 2003, 42, 8283-8293.

[40] R. Viswanathan, M. Palaniandavar, T. Balasubramanian, P. T. Muthiah, J. Chem. Soc. Dalton Trans. 1996, 2519-2525.

[41] J. Muller, A. Kikuchi, E. Bill, T. Weyhermuller, P. Hildebrandt, L. Ould-Moussa, K. Wieghardt, Inorg. Chim. Acta 2000, 297, 265-277.

[42] B. Adam, E. Bill, E. Bothe, B. Goerdt, G. Haselhorst, K. Hildenbrand, A. Sokolowski, S. Steenken, T. Weyhermuller, K. Wieghardt, Chem. Eur. J. 1997, 3, 308-319.

[43] H. Schmitt, R. Lomoth, A. Magnuson, J. Park, J. Fryxelius, M. Kritikos, J. Martensson, L. Hammarstrom, L. C. Sun, B. Akermark, Chem. Eur. J. 2002, 8, 3757-3768.

[44] R. G. Charles, Inorg. Synth. 1963, 7, 184.

[45] M. Chaudhuri, S. Ghosh, J. Chem. Soc. Dalton Trans. 1983, 839-840.

[46] G. S. Hammond, C. H. S. Wu, D. C. Nonhebel, Inorg. Chem. 1963, 2, 73.

[47] G. Aromi, M. J. Knapp, J. P. Claude, J. C. Huffman, D. N. Hendrickson, G. Christou, J. Am. Chem. Soc. 1999, 121, 54895499.

[48] A. L. Spek, J. Appl. Crystallogr. 2003, 36, 7-13.

Received: November 29, 2007

Published Online: January 29, 2008 